\title{
The Unity of Humans and Nature
}

\section{An Interview with Ross Rentea, M.D.}

Russ Mason, M.S.

$\mathbf{R}$ oss Rentea, M.D., is a practicing physician of anthroposophical medicine, a form of holistic medicine that was created by Rudolf Steiner, Ph.D., in the early twentieth century. Dr. Rentea graduated from the University of Chicago School of Medicine, Illinois, and, after his internship, spent 5 years in Europe studying anthroposophical and complementary medicine.

He has been active in family practice for more than 25 years. With his wife Andrea Rentea, M.D., Dr. Rentea created the Paulina Medical Clinic in Chicago, Illinois, which has evolved into a thriving practice. He is a board member of the American College of Anthroposophical Medicine and is board certified in Anthroposophical Medicine.

Dr. Rentea's additional activities include giving numerous lectures as well as training seminars and workshops for professional and lay groups; in addition, he has published a number of articles in peerreviewed medical journals. He has a longstanding interest in researching and creating natural supplements and medicines, and is cofounder and head of the research and development department of True Botanica, ${ }^{\mathrm{TM}}$ L.L.C., a company that offers nutritional and anthroposophical supplements. He lives with his wife and four children in Chicago.

Russ Mason: How did you first become aware of Rudolf Steiner and anthroposophy?

Ross Rentea: I was a freshman at the University of Michigan in Ann Arbor when a professor made an offhand comment that I might be interested in the work of Rudolf Steiner. When I investigated, I was fascinated by the fact that Steiner described processes and events of a spiritual reality that was supposed to underlie our physical world. He claimed to be talking from direct, firsthand knowledge.

It is rare for anybody to say: "I can see all of what I am telling you. I am not basing this on tradition." Moreover, Steiner was teaching a path that could supposedly be followed by [everybody] and they could verify his observations and conclusions. So this is a conscious path and quite different from the mystic path.
RM: Does this path involve meditation or a spiritual practice?

RR: Yes. Meditation leads to spiritual insight, which leads, in turn to a new understanding of the physical world. I am surprised that Steiner is not more widely known. The sheer prolific volume of his work spans more than 360 volumes. He developed an entirely new form of agriculture called biodynamic agriculture and a new method of education called the Waldorf School* - now the largest nondenominational school movement in the world. Steiner was a universal genius.

My parents and friends were terrified that my interest in Steiner was going to distract me from my studies but it had the opposite effect. Anyway, I finished my 4-year college course in 2 years and went on to the University of Chicago School of Medicine.

RM: What do Dr. Steiner's insights reveal about medicine?

RR: His spiritual insights are of therapeutic significance. Rudolf Steiner described the spiritual world in a way that can lead to practical results.

Here is one example: Think of the basic anatomical build that we have as upright creatures. Proceeding from the top down, we have the nervous system with the sense perceptions, then a heart-lung system essentially for respiration and, last, a metabolic/reproductive system.

The plants have an upright position, as we do, but are otherwise opposite to us. The plant perceives the earth through its roots, where the fine tendrils go down; this is similar in function to the nervous system. In the middle, the plant has its respiratory function through its leaves, and at the top of the plant are its reproductive faculties. This is a perfect inversion of the human model. In fact, even the plant's respiratory function is inverted compared to [human beings].

One can see the tremendous medical-therapeutic applications. Carrot $^{\dagger}$ roots have an effect on the eyes and chamomile flower tea is better suited for fighting cramps and discomfort in the abdomen.

*See box entitled About Rudolf Steiner for more details on Dr. Steiner and the Waldorf School.

†For Latin binomials for all herbs in this article, see box entitled Some Herbs Used in Anthroposophical Medicine. 


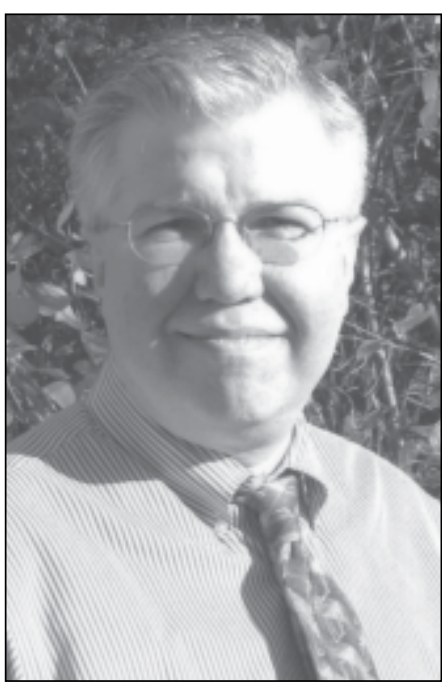

That there is a molecular structure that underlies this. . . [is] all the better.

RM: Are you using these insights in your medical practice?

RR: Absolutely. Rudolf Steiner's insights are now being confirmed by modern scientific research both within and outside of anthroposophical circles. At the time, however, some of Steiner's statements appeared outlandish to his contemporaries.

Ross Rentea, M.D., Paulina Medical Clinic.

RM: What is an example of Dr. Steiner's insights?

RR: Take the herb turmeric for example. Steiner talked, about turmeric as a plant that has the ability to "extract illness out of the body." Today there are hundreds of formulations using turmeric, based on research published in many peerreviewed papers.

Steiner also talked about the arnica plant as being able to assist vital life and soul forces inside the body, and to help with a comprehensive healing. Only recently have researchers outside of anthroposophical circles determined that the active chemical of the arnica plant, the sesquiterpene lactones, indeed have unexpectedly powerful anti-inflammatory and regenerative properties.
In another area, Rudolf Steiner predicted that we would be able to do specific urine testing to determine the function of the brain. Well, we are now at the point where we can reliably measure neurotransmitter levels in the urine.

\section{RM: Did anthroposophy lead you to become a physician?}

RR: I was always interested in being a doctor and began my university path with that goal in mind. However, the study of Rudolf Steiner influenced the type of medicine I wanted to practice, which is primarily holistic medicine. Unfortunately, much of holistic medicine today seems to just replace pharmaceuticals with naturally derived substances and then suggests meditation so that one strengthens the mind and relaxes the body. There is nothing wrong with that but there should be more to it.

Through anthroposophy I've come to understand that we can describe the impulses of thinking, feeling, and willing quite specifically and that there are substances that are more uniquely suited to one spiritual activity or another.

One of the more interesting aspects of anthroposophical medicine is that it nearly reverses the paradigm "treat the physical body with a physical substance and the mind with a mind exercise" by saying, "never think of substance without spirit; never think of spirit without substance."

\section{RM: Can you give an example?}

RR: Yes, but you need to be willing to think outside the box. Imagine for a moment that any thought or feeling might be ableas a separate spiritual force in the world-to go through a process where, at the end, it would become a crystalline physical substance.

Take, for example, the experience that we have when we taste the bitter herb gentian tincture. It certainly gives us a strange feeling in the mouth but also the sensation that our entire soul is

\section{About Rudolf Steiner}

Rudolf Steiner, Ph.D. (186I-1925), was a German-born philosopher, scientist, and "seer" who found his life's work in the realms of consciousness and cognition. His techniques for the development of awareness of nature's cycles, daily meditation, and concentration practices - as well as clear, critical thinking - led individuals to reach higher levels of consciousness. He believed that working with the spiritual worlds could enrich the life of the individual and, consequently, the world.

A university student of science, Dr. Steiner later earned a doctorate in philosophy. He edited the scientific writings of Goethe, whose approach — based on an intensified, selfless observation of nature-became a source of inspiration for Dr. Steiner. His doctoral dissertation explained Fichte's theory of knowledge: that people are restricted in thought only by the limits of their minds and should be restricted in speech only as necessary under self-imposed standards of goodness, universal knowledge, and truth.

Dr. Steiner later expanded and published this dissertation as Truth and Science (which was also published under the title Truth and Knowledge) in 1891. ${ }^{\mathrm{a}}$ In 1894, he published The Philosophy of Freedom, ${ }^{\mathrm{a}}$ which he felt to be his most important philosophical work.

Dr. Steiner brought forth from his spiritual experiences an abundance of scientific, medical, agricultural, social, educational, architectural, and artistic renewal. He called this science of spirit anthroposophy, meaning "wisdom of the human being."

The author of nearly thirty books, Dr. Steiner also gave thousands of lectures on a wide range of subjects. He initiated Waldorf education, ${ }^{b}$ biodynamic farming and gardening, a new approach to the care and education of people with disabilities, anthroposophical medical work, and an artistic and therapeutic movement called eurythmy (see text for explanation of this therapy). More information on his ideas may be found at the Anthroposophical Society in America ${ }^{\mathrm{C}}$ and the Anthroposophical Press. ${ }^{\mathrm{d}}$

aThe two papers appear to have been early college papers and were incorporated into The Philosophy of Freedom, also known as The Philosophy of Spiritual Activity. The book was translated by Rita Stebbing in 1988 and published by Rudolf Steiner Press, in London, UK, 1992.

bWaldorf education is a unique form of education from preschool through high school, which is based on the view that the human is a being of body, soul, and spirit. The specific methods used in Waldorf schools come from the view that the child develops via a number of basic stages from childhood to adulthood. The Waldorf curriculum is designed to work with the child through these stages of development. For more information, visit: http://www.waldorfanswers.org/.

cAnn Arbor, MI.

dGreat Barrington, MA 


\section{To Contact Drs. Ross and Andrea Rentea}

Ross Rentea, M.D., and Andrea Rentea, M.D.

Paulina Medical Clinic

3525 West Peterson Avenue, Suite 61I

Chicago, IL 60659

Phone: (773) 583-7793

Fax: (773) 583-7796

e-mail: ross.rentea@truebotanica.com

Website: www.truebotanica.com/

more constricted. These are not easy matters to describe. But this makes clear why, in an anthroposophically inclined holistic medical practice, one would treat a patient who is "scattered" in his or her demeanor with a bitter substance like the gentian herb.

The flip side to this is that, when faced with a physical pathology, one might actually gain more insight into it by delving into the biography of the patient than by just merely doing another laboratory test.

\section{RM: Again, can you give an example?}

RR: I recently saw a 54-year-old male who had a complete colon removal due to ulcerative colitis. He was still not feeling well, had lost over 65 pounds, and did not understand why this calamity had befallen him. I could have given him some anti-inflammatories, nutritional advice, and so forth, but instead I spent some time with him, asking questions about his life. I felt that I could get some answers about the nature of his illness by looking at the events that had happened to him in the past.

I know from my anthroposophical studies that one's life forces and spiritual development are connected to a 7-year cycle. In other words, events that happened as early as 7 years prior to an event will, in general, indicate which direction the problem has come from. In the case of this patient, he had had a heart valve replacement 7 years previously. Exactly 7 years before that, he had been diagnosed with his valvular heart disease; and 7 years prior to that he described going through events in his life with "a heavy heart."

I felt that his digestive inflammation had its origin in the cardiovascular system, so I prescribed a special form of colloidal gold. We often use a variety of diluted and specially prepared metals in anthroposophical therapy, and gold is used for the heart. Since the heart has a lot to do with feelings, and a certain levity needed to be brought to this patient, I also recommended anthroposophical artistic therapies. With these treatments, his condition improved.

\section{RM: Please explain about the artistic therapies.}

RR: Anthroposophy has led to new artistic therapies, such as a form of movement therapy called eurythmy. It is based on Steiner's insight that for each consonant, vowel or specific word uttered in human speech, there is a corresponding movement that outwardly expresses these utterances, and that each combination of these movements leads to a specific therapeutic effect.

\section{Some Herbs Used in Anthrosophical Medicine}

\begin{tabular}{ll} 
Common name & Latin binomial \\
Arnica & Arnica montana \\
\hline Carrot & Daucus carota \\
\hline Chamomile & Matricaria spp. \\
Gentian & Gentian spp. \\
\hline Mistletoe & Viscum album \\
\hline Rosemary & Rosmarinus officinalis \\
\hline Turmeric & Curcuma spp. \\
\hline
\end{tabular}

As you may imagine, there are an infinite number of possibilities: The field is opening for many researchers of movement therapy. Additionally, anthroposophical research is also beginning to penetrate the spiritual significance of musical scales and, similarly, we are deepening our understanding of the use of color therapy in painting.

RM: How did you train to become an anthroposophical doctor?

RR: Once I was accepted into medical school I was kept plenty busy. Anthroposophy gave it meaning but I often had to remind myself to stop admiring the beauty of what I was learning-that medical facts were required in order to pass my exams. In my senior year I chose to research the pharmacological properties of the immune modulator Iscador, or mistletoe.

Iscador goes back to the 1920s, when Steiner was asked to suggest a treatment for cancer. Arising from a spiritual vision, Steiner selected mistletoe, and the first patients were successfully treated with his formulation.

\section{RM: Please explain a little bit more about that.}

RR: An injection is made from a mixture of extracts from both the summer and winter mistletoe juice, then processed by an ultra-high-speed centrifugation process. That Steiner would select this plant is of interest, since mistletoe had been used in herbal and traditional medicine for centuries for various purposes such as epilepsy, infertility, and high blood pressure.

Previous to Steiner, however, mistletoe had never been used in the treatment of cancer or for immune therapy. To me, this presented a unique opportunity to add some well-designed studies to one of the most typical anthroposophical therapies. The results of my research were so surprisingly positive that my supervising professor was hesitant to publish the paper, even after he had my work replicated by one of his own technicians. The results pointed to the ability of the mistletoe to kill tumor cells while also stimulating T-lymphocytes. These seemed to be contradictory activities, particularly at a time when the concept of immune modulation was still in its infancy.

It was personally gratifying to confirm - in the laboratory, at a molecular level—what Rudolf Steiner had discovered from spiritual insight. Incidentally, one of our findings was that animals, pretreated with Iscador, were protected from the bladder-cancer-causing effects of some carcinogenic agents. 
We were excited that this might have implications for the industries where exposure to certain chemicals causes an increased incidence of bladder cancer among workers. I was disappointed to see that nobody picked up this lead. Recentlynearly 30 years later-the effects of mistletoe preparations on the bladder have been confirmed in a clinical study. However, the use of mistletoe extract for its anticancer activity is now widespread in the world, particularly in Europe.

During this time, I met Andrea, my future wife. She was a student at the Chicago Medical School. We married while we were still in our respective medical schools, both of us active in the anthroposophical world. After medical school, we went to Europe for 5 years to study internal medicine and psychiatry at various anthroposophical clinics.

We had the opportunity to work with patients suffering from various chronic and acute illnesses, as well as patients with schizophrenia and severe depression. All were being treated almost exclusively with remedies made from herbal preparations, metal formulations, and glandulars, as well as external applications. Many of the treatments we learned were new to us.

More importantly, we engaged in botanical and geological studies and meditations, and participated in study circles, all of which gave us the opportunity to shift our thinking from a purely molecular point of view to a more holistic, functional perspective. When we came back to the United States, we opened the
Paulina Medical Clinic in Chicago, where we have been a practicing for the last 20-plus years.

RM: Let's talk about your practice. How do you treat illnesses?

RR: Some problems must be treated conventionally if we don't have enough anthroposophical insight into a specific pathology. However, there are anthroposophical treatments that we can apply successfully.

For example, I often treat with Bidor for headaches. Bidor is a remedy containing a combination of iron, sulfur, and quartz that can normalize the inflammation that often leads to migraine headaches. It is successful often enough to be a satisfactory treatment. We also use a number of remedies that are similar to the ones used in homeopathy but with a totally different set of indications. We use mistletoe preparations to help the immune system; we use herbal and trace mineral combinations made via special pharmaceutical processes to fight inflammation.

RM: Are your patients happy with your treatments?

RR: I hope they are. Our patients are presented with innovative ideas that help them get better while reaffirming their human dignity and individuality. We take time at the visit and do not rush them. We make house calls-not every day perhaps but frequently enough. We also try to be affordable. Wherever there is a financial hardship we apply a sliding scale or reduce our visit fees.

\section{Resources for Anthroposophical Medicine}

According to Dr. Rentea, many U.S. physicians and other health care practitioners use a variety of anthroposophical modalities in their practices; this appears to be a growing trend. Key anthroposophical organizations are listed below.

\section{Professional organizations}

\section{Anthroposophical Society in America \\ 1923 Geddes Avenue \\ Ann Arbor, MI 48I04-I797 \\ Phone: (734) 662-9355 \\ Fax: (734) 662-I727 \\ e-mail: information@anthroposophy.org \\ Website: www.anthroposophy.org/}

\section{Artemisia \\ Association for Anthroposophical \\ Health Professionals \\ 5909 SE Division Street \\ Portland, OR 97206 \\ Phone: (503) 235-9067 \\ Fax: (503) 234-2367 \\ Website: www.artemisia.net/}

\author{
Association for Therapeutic Eurythmy in \\ North America (Athena) \\ I08I Dickens Drive \\ Santa Rosa, CA 9540I \\ Phone: (707) 568-4288 \\ Fax: (707) 568-4242 \\ Website: www.artemisia.net/athena/index.htm
}

Physicians' Association for Anthroposophical Medicine (PAAM)

1923 Geddes Avenue

Ann Arbor, MI 48I04-I797

Phone: (734) 930-9462

Fax: (734) 662-1727

Website: www.artemisia.net/paam/index.htm

\author{
Anthroposophical Nurses Association of America (ANAA) \\ 5909 SE Division Street \\ Portland, OR 97206 \\ Phone: (503) 235-9067 \\ Fax: (503) 234-2367 \\ Website: www.artemisia.net/anaa/index.htm
}

\author{
Rhythmical Massage Therapy Association (RMTA) \\ of North America \\ c/o Micky Leach \\ 250I West Zia Road \\ Santa Fe, NM 87505 \\ Phone: (505) 438-0I56 \\ Website: www.artemisia.net/rmta/index.htm
}

\section{Clinic}

Rudolph Steiner Health Center

2385 South Huron Parkway

Ann Arbor, MI 48I04

Phone: (734) 677-7990

Fax: (734) 677-799I

e-mail: csammed@earthlink.net

Website: www.csamwebsite.org/index.htm 
RM: How do patients hear about you?

RR: Most of them are referred by word of mouth, because the referring person had a successful treatment from us. We don't advertise. I would say that most of our patients have never heard of Rudolf Steiner or anthroposophical medicine when they come to see us. They come because they have an aversion towards intrusive medicine, hospitalization, and the impersonal way in which medicine is sometimes practiced in other offices. But we never proselytize, and we only discuss the spiritual aspects of anthroposophy if specifically asked.

RM: How have your allopathic colleagues reacted to your ideas?

RR: Times are changing for the better. When I first applied for hospital privileges I explained to the committee that anthroposophical medicine had to do with ethics in medicine, and left it at that. It was true of course, but it hardly began to describe the reality behind anthroposophy. Back then, most of our colleagues preferred not to have anything to do with us outside of taking care of the patients on the ward. Today, we live in a time when the public has driven forward the acceptance of complementary medicine.

RM: How does one train to become an anthroposophical doctor?

RR: The Physicians' Association for Anthroposophical Medicine offers excellent training for doctors in the U.S. The course is led by Dr. Alicia Landman-Reiner [M.D.], a graduate of Harvard Medical School [Boston, Massachusetts] who has many years of clinical experience and a deep respect for anthroposophy. The courses are given in installments of 1 week at a time over the course of 2 years.

However, even if a doctor does not intend to actually practice anthroposophical medicine, it is worthwhile to study it in order to achieve higher personal development. Steiner left detailed instructions for a path of spiritual development specifically for the physician. For example, Steiner taught a course for young doctors where he gave a step-by-step path involving seven meditations. These meditations enable the doctors to grow spiritually in such a way that they should be able to observe the natural world more accurately, enhance their healing abilities, develop more compassion for their patients, and increase their diagnostic abilities.

RM: Are there many anthroposophical physicians in this country?

RR: The numbers are growing and we have several helpful professional organizations. [See box entitled Resources for Anthroposophical Medicine.] In Europe, however, there are approximately 3000 anthroposophical doctors. In Germany, anthroposophical physicians sit on all the relevant government commissions that regulate the use of ACM.

RM: Do all anthroposophical doctors have the same basic approach?
RR: No. Each practitioner is individualistic, and that makes for a nice mix. There is also quite a breadth of interests among anthroposophical physicians.

For example, Gerald Karnow [M.D.], in Chestnut Ridge, New York, sees patients but is also active in the Fellowship Community, a retirement community/nursing home where medical concerns are integrated with ancillary activities such as farming, printing medical books, and more. They have been so successful at what they're doing that the State of New York is considering them a model to be followed by other institutions.

The founder of the Fellowship Community is Paul Scharff [M.D.], from Spring Valley, New York. He has practiced anthroposophical medicine for over 40 years and is one of the pioneers of anthroposophical medicine in the U.S. He is a tremendous individual from whom Andrea and I have learned enormously.

RM: Is it possible to become board certified in anthroposophical medicine?

RR: Yes, but we are trying to develop even higher medical standards, so that the public will have a better sense of the qualifications of an individual practitioner. There is now board certification and nobody has been grandfathered in. So when Andrea and I call ourselves board-certified anthroposophical physicians, it is because we passed an oral examination, presented five cases for review, wrote a peer-reviewed article, and generally proved mastery in the field.

RM: Can you tell us more about how you educate other professionals?

RR: I make regular presentations at annual workshops on anthroposophical medicine both here and in Europe, and organize conferences on related topics. We have periodically had medical school residents come to our office during their elective time. The residents that we see nowadays clearly are more inquisitive-even those who don't necessarily agree with us. I have also lectured in medical schools on the anthroposophical treatment of diabetes with rosemary plant extracts, the use of mistletoe extracts in immune therapy, a new approach to pediatrics, and other applications.

\section{RM: What led you to start your company, True Botanica?}

RR: After many years of practice, and being repeatedly unable to get the anthroposophical supplements we needed, we decided to make some fresh formulations ourselves. Three of us, Mark Kamsler [M.D., Deerfield, Wisconsin], Andrea, and I started the company at the beginning of 2004. We now have a line of anthroposophical supplements that we are constantly expanding. These are innovative products that contain, for example, a mixture of all three parts of a plant: roots; leaves; and flowers. Or they contain biodynamically treated herbs that have been sprayed with 
therapeutic substances so that the substances become more bioavailable, or formulations that have been mixed with a specially engineered mixer designed by a Swiss company.

Our primary concern is to be able to help our patients but there are certain social principles that we adhere to as well. These include supporting organic farmers, promoting a holistic lifestyle, and supporting educational activities. Incidentally, Andrea-in addition to her other activities-also travels as a consultant for Waldorf Schools.

True Botanica has also launched a line of organic, natural cosmetics. Our intent is that the sale of these body-care products will generate enough funds to initiate clinical and laboratory research.

RM: What, do you think, will be the future of anthroposophical medicine, given the technological advances of allopathic medicine?
RR: The more we go into the depth of molecular, genetic, or atomic understanding, the more the need is increased to answer questions about the meaning of life, and to develop corresponding moral values. This may appear to be a paradox perhaps but a paradox is nothing more than an apparent contradiction that reveals a deeper truth.

RM: Thank you very much, Dr. Rentea, for an interesting interview.

RR: You're welcome. It's been a pleasure.

To order reprints of this article, write to or call: Karen Ballen, ALTERNATIVE \& COMPLEMENTARY THERAPIES, Mary Ann Liebert, Inc., 140 Huguenot Street, 3rd Floor, New Rochelle NY 10801, (914) 740-2100. 